Article

\title{
Supporting a Design Driven Approach to Social Inclusion and Accessibility in Transport
}

\author{
Russell Marshall ${ }^{1, *}$, Steve Summerskill ${ }^{1}$, Keith Case ${ }^{2}$, Amjad Hussain ${ }^{3}$, Diane Gyi ${ }^{1}$, Ruth Sims ${ }^{4}$, \\ Andrew Morris ${ }^{1}$ and Jo Barnes ${ }^{1}$ \\ ${ }^{1}$ Loughborough Design School, Loughborough University, Loughborough, LE11 3TU, UK; E-Mails: \\ r.marshall@lboro.ac.uk (R.M), s.summerskill2@lboro.ac.uk (S.S.), d.e.gyi@lboro.ac.uk (D.G.), \\ a.p.morris@lboro.ac.uk (A.M.), j.barnes@lboro.ac.uk (J.B.) \\ ${ }^{2}$ Mechanical and Manufacturing Engineering, Loughborough University, Loughborough, LE11 3TU, UK; E-Mail: \\ k.case@lboro.ac.uk \\ ${ }^{3}$ Department of Industrial and Manufacturing Engineering, University of Engineering and Technology, 54890 Lahore, \\ Pakistan; E-Mail: chamjad@gmail.com \\ ${ }^{4}$ Department of Psychology, University of Derby, Derby, DE22 1GB, UK; E-Mail: r.sims3@derby.ac.uk \\ * Corresponding author
}

Submitted: 1 December 2015 | Accepted: 5 February 2016 | Published: 7 June 2016

\begin{abstract}
This paper presents research into the area of public transport and accessibility, addressing the support of practitioners in achieving socially inclusive solutions to the mobility issues of diverse populations. For decades, social policy has been underpinned by a stereotyping of populations into simplified sub groups: old, young, disabled, etc. and thus solutions often fail to properly address the richness of human variability. These shortcomings are often 'managed' through the ability for people to adapt, however, this is not a sustainable way in which to build a socially inclusive transport infrastructure. A software design tool called HADRIAN is presented. This tool provides a means to evaluate designs for their physical inclusiveness through the use of a virtual user group. This virtual user group is the embodiment of over 100 people that can be used to assess an existing or proposed design and to gain an understanding of what may be done to improve its accommodation. A case study exploring the use of the tool is described together with work in exploring the correlation of the individuals within the HADRIAN system with data on the UK population as a whole and how the inclusion or exclusion of individuals with specific characteristics can be used to inform a more representative view of the inclusiveness of a design.
\end{abstract}

\section{Keywords}

accessibility; design change; digital human modelling; HADRIAN; mobility issues; SAMMIE; simulation; social inclusion; transport

\section{Issue}

This article is part of the issue "Transport Policy and Social Inclusion", edited by Miriam Ricci, Graham Parkhurst and Juliet Jain (University of the West of England, UK).

(C) 2016 by the authors; licensee Cogitatio (Lisbon, Portugal). This article is licensed under a Creative Commons Attribution 4.0 International License (CC BY).

\section{Introduction}

It is often stated that transport can have a direct positive impact on social inclusion by providing people with access to services such a healthcare and shopping, to help them get to a place of work, and to increase their interaction with others both on the transport itself and at their destination (Mackett, Achuthan, \& Titheridge, 2008). Transport also appears to be of particular importance to older users and the ageing population has 
the potential to significantly affect public transport planning in future years (Barnes et al., 2015; Green, Jones, \& Roberta, 2014). The inverse is also true in that social exclusion as a result of transport exclusion is a major concern, particularly as people age and potentially lose access to personal transport as they have to give up driving, as their mobility decreases, as they retire and potentially have reduced income, these factors are also prevalent in those that have disabilities (Green et al., 2014; Mackett $\&$ Thoreau, in press). In a survey by the Department for Transport (2001) that considered the needs of older travellers over a third of respondents aged 60 or over said they would like to travel more and also identified both transport related and health related barriers to this occurring. Successive governments in the UK have explicitly recognised these links and have put in place policies intended to improve the lives of older people through access to transport. For example concessionary travel on buses has been offered to children, older people and people with disabilities for many years. Currently referred to as the concessionary travel pass (CTP), free bus travel appears to have resulted in an increase in the bus usage of older people and to have provided an increase to services. However, the success of the aims of the policy to provide free travel are not necessarily clear. For example, for many of those who are eligible for free travel, the availability of the CTP would have coincided with retirement and thus may have increased their bus usage regardless of free travel (Mackett, 2014). Another issue concerns safety, whilst public transport is generally considered to be safe, more than 5000 people are injured on buses and more than 300 killed or seriously injured in the UK each year and older people are over represented as bus/coach casualties (Department for Transport, 2013).

These issues highlight one of the core difficulties in policy generation, in that it is often very difficult to predict the outcome of a policy change or to investigate the detailed causal factors behind some of the observed population trends. In the case of concessionary travel there is much evidence to suggest it has addressed its aims, however there is also evidence to suggest that such policies have other unforeseen effects and potentially do little to address social inclusion due to the presence of other barriers not associated with cost (Musselwhite \& Haddad, 2010; Rye \& Myku$\mathrm{ra}, 2009$ ). For some considerable time it has been well recognised that the journey from public policy to a design solution is problematic and ideally should include causation, evaluation and instrumentation (Linder \& Peters, 1984). Furthermore it appears that policy makers, particularly in the case of local authorities involved in transport planning, do not tend to innovate, but rather rely on pre-conceived solutions that focus on supply rather than demand (May, Kelly, Shepherd, \& Jopson, 2012).
One means of aiding policy makers, planners and designers to gain a greater understanding of any planned change on social inclusion, or to retrospectively evaluate a situation to inform change, is to utilise modelling and simulation tools. There have been a number of modelling and simulation approaches that have been explored that utilise mapping tools such as GIS (geographic information systems) for example, CAPITAL (Church, Frost, \& Sullivan, 2000), LUPTAI (Yigitcanlar et al., 2007) and AMELIA (Mackett et al., 2008) amongst others (Ford, Barr, Dawson, \& James, 2015; Karou \& Hull, 2012). However the majority of these approaches have limited capability to address individual user needs within a broader population based approach. As such, the richness of end user requirements can be lost in the generalisation and homogenisation of groups within the population.

This paper presents ongoing research into 3D modelling and simulation and the use of digital human modelling (DHM) tools to explore and inform accessibility and inclusion. Through the use of a unique database on older and disabled people that forms a virtual user group, together with an existing DHM tool called SAMMIE (Porter, Marshall, Freer, \& Case, 2004), a prototype tool called HADRIAN has been developed. A case study of the use of the tool is presented together with research into exploring how inclusivity explorations with individuals can be used to inform a broader understanding about accessibility for populations.

\section{HADRIAN}

HADRIAN is an inclusive design tool aimed at supporting practitioners in inclusive design practice, be they designers, architects, town planners etc., through the exploration of the accessibility of their ideas prior to implementation. The tool is the output of iterative research and development initially funded by the Engineering and Physical Sciences Research Council (EPSRC) as part of their Extending Quality Life (EQUAL) Programme. This process began with a stakeholder review of requirements (Gyi, Porter, \& Case, 2000; Oliver, Gyi, Porter, Marshall, \& Case, 2001), followed by a pilot study exploring data collection methods (Marshall, Case, Oliver, Gyi, \& Porter, 2002), and then progressed into the structural development of a software task analysis tool and the creation of a user database through the collection of a wealth of data on 102 individuals, the majority of whom are older and/or disabled (Marshall, Case, Porter, Sims, \& Gyi, 2004; Porter et al., 2004). The resulting prototype tool (Marshall et al., 2010) addressed two main concerns: 1 . the applicability of the data used to inform designers and simulation tools in inclusive design practice, notably data on human variability, joint range of motion, behaviour and coping strategies; and 2. a means of accessing simulation 
functionality that is more attuned to the working methods of designers.

Figure 1 shows a prototype of the database of individuals. A significant amount of data is available including: age, gender, occupation, any registered disabilities, anthropometry (body measurements), joint range of motion, task capability and behaviour video's, reach range, and a selection of questionnaire responses regarding views on transport use. The data themselves form a potentially useful resource for practitioners, particularly in fostering an understanding and empathy with users and providing insights into the effects of ageing and the significant variability in disability.

The data in the database can also be used to support DHM application. HADRIAN works together with the SAMMIE DHM system by providing data on the creation of human models for simulation purposes. In this manner HADRIAN provides a virtual user group for user trials conducted in the digital environment. Interaction points, workplaces, and environments can all be 3D modelled and then evaluated with the virtual users as shown in Figure 2. Using a task-based methodology tasks can be defined and assessed for each individual as a virtual analogue of the real-world equivalent.

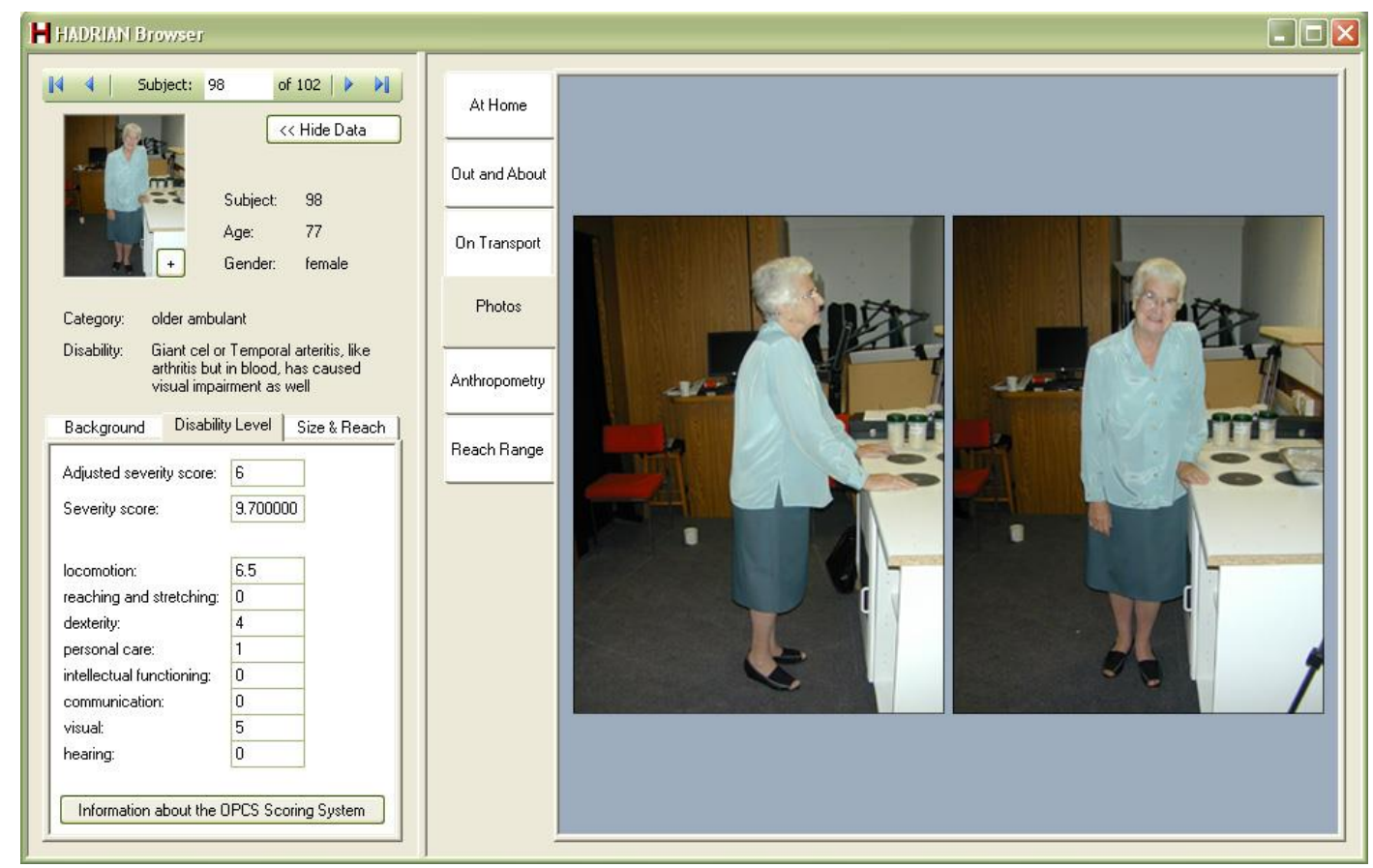

Figure 1. HADRIAN database interface showing overview information on the individual (left) and a range of detailed information in this instance photos for empathy (right).

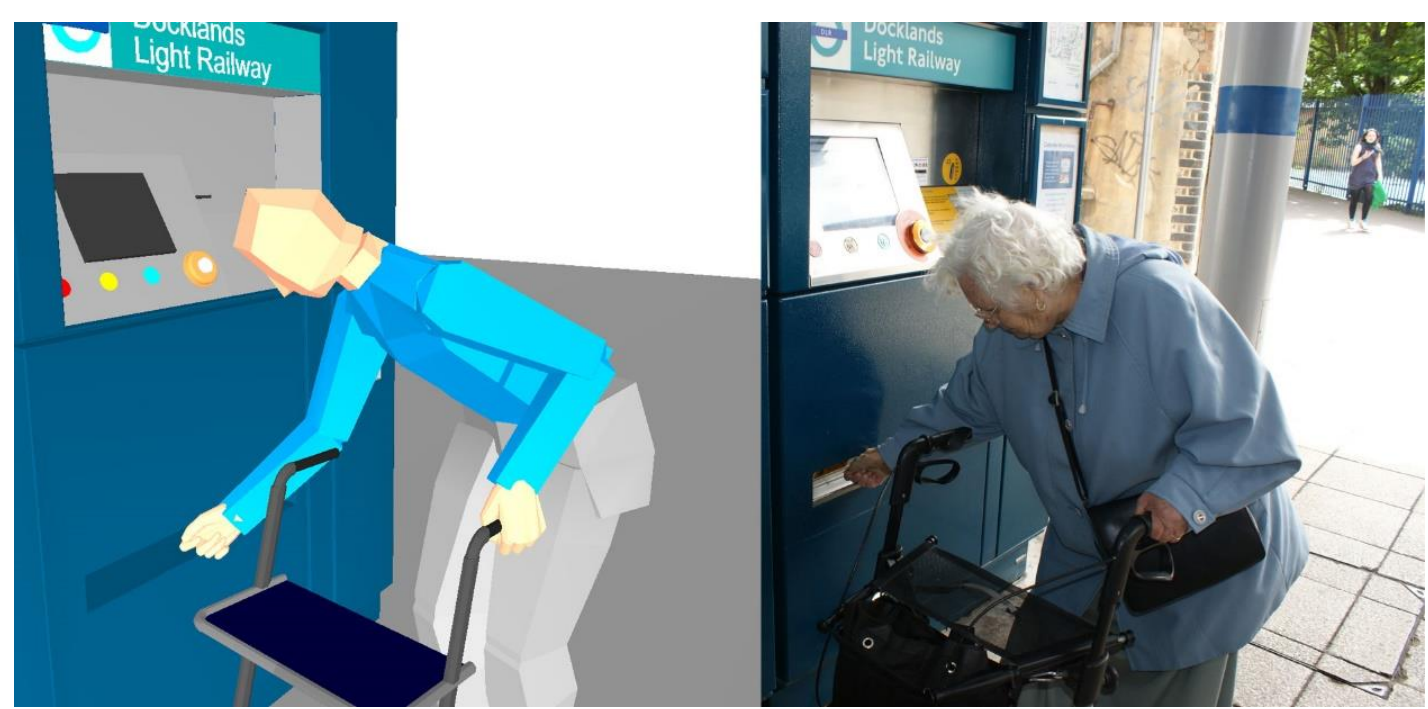

Figure 2. HADRIAN-SAMMIE simulation of interacting with a ticket machine (left) and real-world validation (right) during trials at the DLR station in Greenwich, London. 


\section{The Use of HADRIAN Data in a Public Transport In- clusion Case Study}

Informed by concerns regarding the prevalence of bus travel with older users and the number of injuries and fatalities that occur each year, feasibility research has been conducted aimed at improving safety for older public transport users (OPTU). Funded by the Medical Research Council under their Lifelong Health and Wellbeing programme, part of the OPTU project focused on the use of a human modelling approach as a means of exploring issues and evaluating design interventions. Based upon an analysis of the police accident database STATS_19 exemplar case studies were identified (Barnes et al., 2015). To illustrate the process, one of those case studies is outlined here. This case study focused on the use of a typical bus design operated in the UK and any causal factors associated with accidents to standing passengers that represent $41 \%$ of older casualties (Barnes et al., 2013).

To perform the evaluation a representative bus model was required. A typical example of a large bus was identified from a local operator and permission sought to access the vehicle whilst not in service. To capture the vehicle geometry in an expedient manner a FARO LS 3D Scene scanning system (FARO, 2015) was used to digitally capture the interior of the bus. The system utilises a 360-degree laser scanner mounted on a tripod that digitally encodes everything in the line of sight. The tripod was positioned in three locations along the length of the bus and scans were captured. Each scan takes approximately 60 seconds however with associated set-up time and planning of the data capture the complete scan time on site was approximately one hour. The scans initially take the form of a point cloud consisting of hundreds of thousands of data points. Using specialist software in the form of Geomagic (3D Systems, 2015) the three scans were merged into a single dataset, noise and unwanted scan geometry were removed to produce a coherent point cloud.

The point cloud was then decimated to reduce the complexity down to a manageable level and finally tessellated to turn the points into a triangular mesh of surfaces as shown in Figure 3. Further work was required to break the complete bus model down into functional elements such as seats, handles, rails etc. Holes were patched and geometry missed due to lineof-sight occlusion was modelled manually. To complete the process the geometry was imported into the SAMMIE DHM system where simple external geometry was added and textures applied. The original bus and the resulting models are shown in Figure 4.

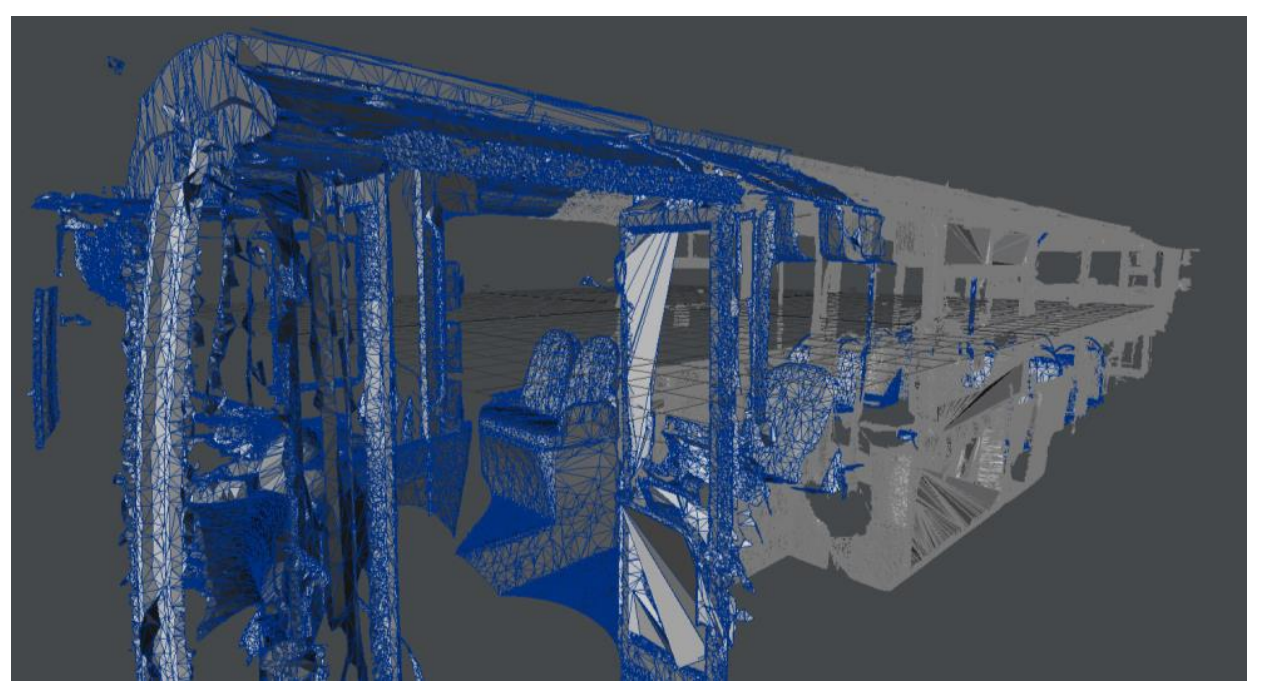

Figure 3. Tessellated 'point cloud' resulting from three scans combined to create the bus geometry.
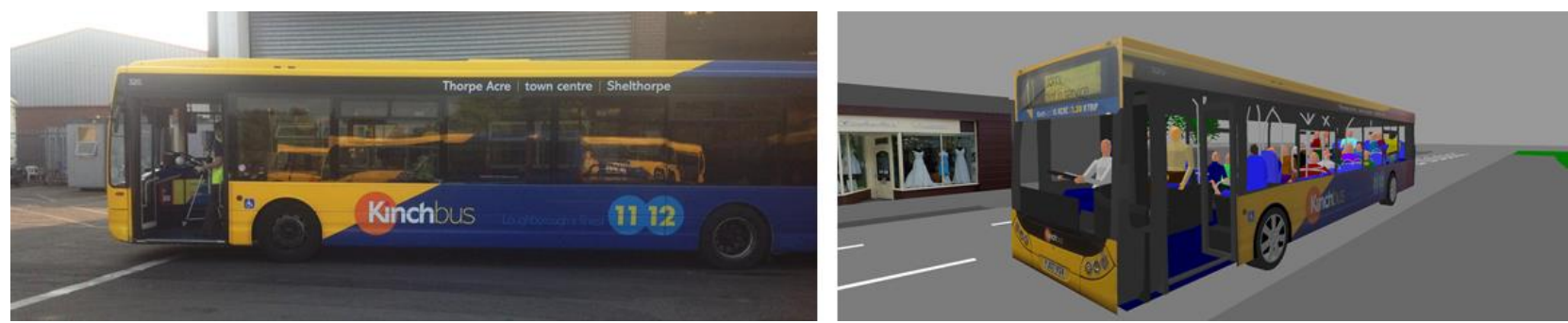

Figure 4. Bus used for the modelling activity, a 42 seat Kinchbus No 12 (left) and the resulting model in SAMMIE (right). 
The use of a digital modelling process to evaluate this type of scenario has many advantages including the ability to model a broad range of users, to explore representative scenarios in a manner that does not face the real world issues of participant recruitment, ethics and safety and problems associated with taking a bus out of service for an extended period. However the DHM approach is not without its limitations. DHM tools typically support static evaluations of key-frame postures and tasks. However, accidents are invariably dynamic events and so there is a requirement for some hypothesis in the recreation of the accident event. Dynamic modelling technology is available but was deemed beyond the remit of this research. Taking a static approach still provides the potential to evaluate key design parameters that may prove to be causal factors in accidents and identify potential design countermeasures.

Figure 5 shows the resulting setup of the model within the SAMMIE DHM system. The bus has been populated to provide a realistic case study environment and to provide the potential to explore the impact of passengers on accessibility, particularly to hand holds that may be obstructed by passengers seated or standing.

The methodology for the case study focuses on the ability for a standing passenger to be able to hold on to the vehicle whilst traversing along the vehicle. Standing passengers are at greatest risk when the vehicle moves off or comes to a stop e.g. whilst passengers are making their way to a seat, or whilst they are stood with a view to making their way to the front to alight. Whilst causation of any particular accident in these conditions has many contributing factors, the approach taken was to assume that passengers should be able to hold on and brace themselves against any acceleration or deceleration at all times whilst on the vehicle.

Using HADRIAN in its intended manner all 102 participants in the virtual user group would be evaluated.
However, for expediency a single participant was used to demonstrate the principle. The analysis explored the scenario using participant number 13 (P13) in the HADRIAN database. P13 is a 69 year old female with good mobility who lives independently. A female participant was selected as STATS_19 showed that $78 \%$ of accidents occurred to female passengers, in addition P13 had a relatively small stature $(1537 \mathrm{~mm}=10$ th \%ile UK Female) with average joint range of motion (mobility), see Figure 6. P13 provides a relatively extreme case in their ability to traverse along the vehicle whilst maintaining a hand hold due to having short arms. Other participants in the HADRIAN user group would provide alternative challenges such as limited mobility and/or the need to use a stick or a frame.

The analysis involved positioning and posturing of the digital human model to explore the opportunity to hold onto at least one of the hand holds throughout the length of the vehicle. Where hand holds were out of reach the analysis would identify the failure of the task and highlight the possible need to explore design interventions. Wherever possible a constant grip of a hand hold was maintained such that the human model would essentially always be holding on with at least one hand hold to give themselves some chance of bracing if required (Figure 7).

The analysis highlighted a number of potential issues that would be faced by someone such as P13. Figure 8 and Figure 9 show that when a passenger has to move beyond the forward facing seating area to the transverse seating area, the ability to maintain a hand hold becomes problematic. Once the passenger commits to holding onto the left hand curved handle and steps forward there is no convenient handle on the right hand side. The next handle on the right is out of reach for $\mathrm{P} 13$.

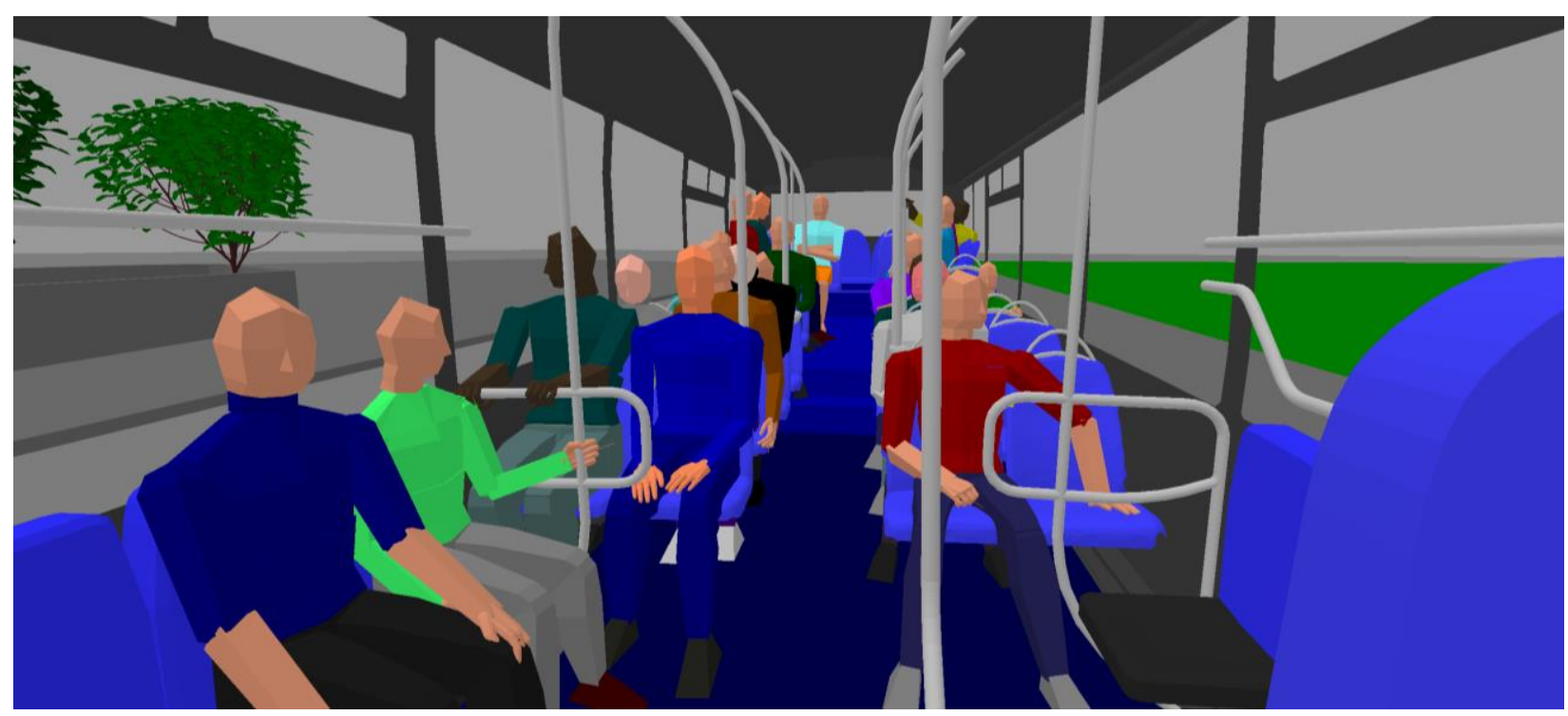

Figure 5. Bus interior modelled and populated in the SAMMIE DHM system. 


\section{COGITATIO}

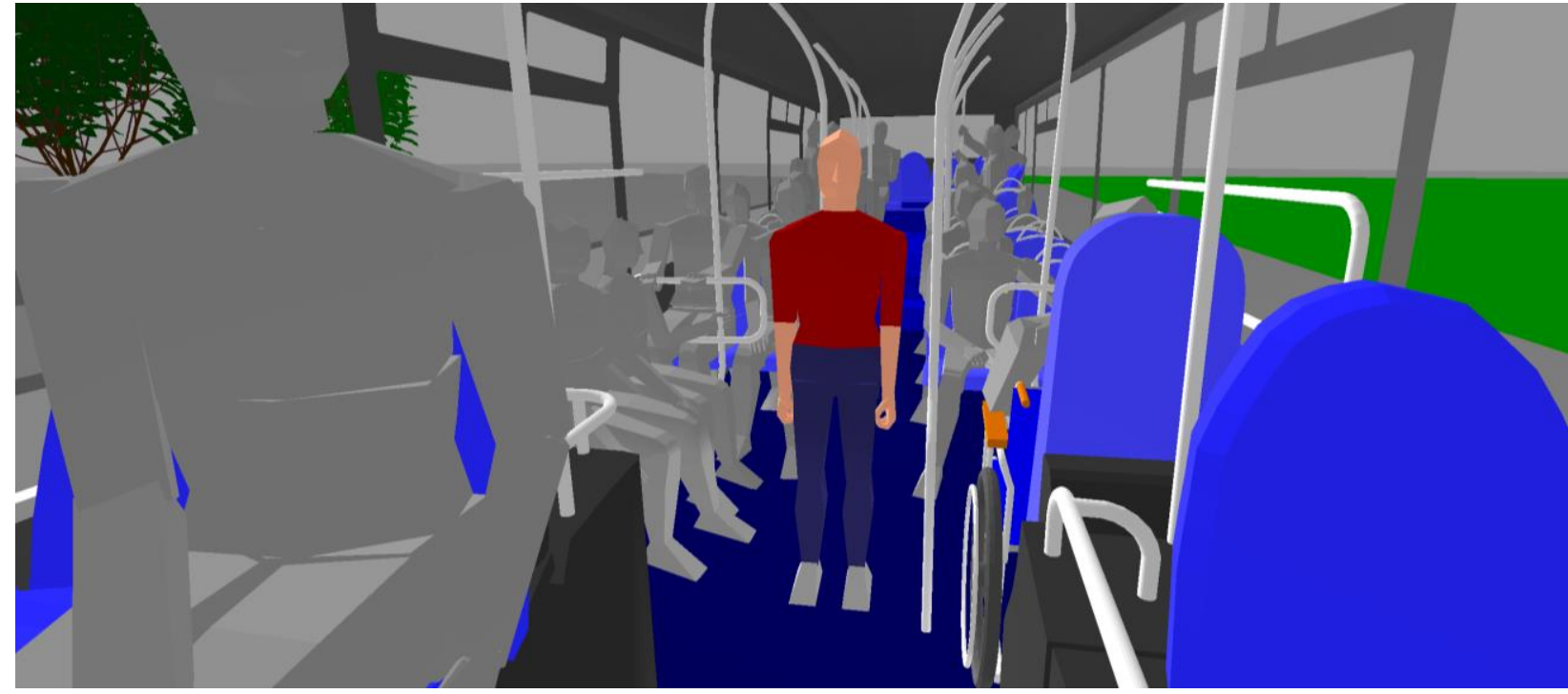

Figure 6. HADRIAN P13, UK Female digital human model within the bus.

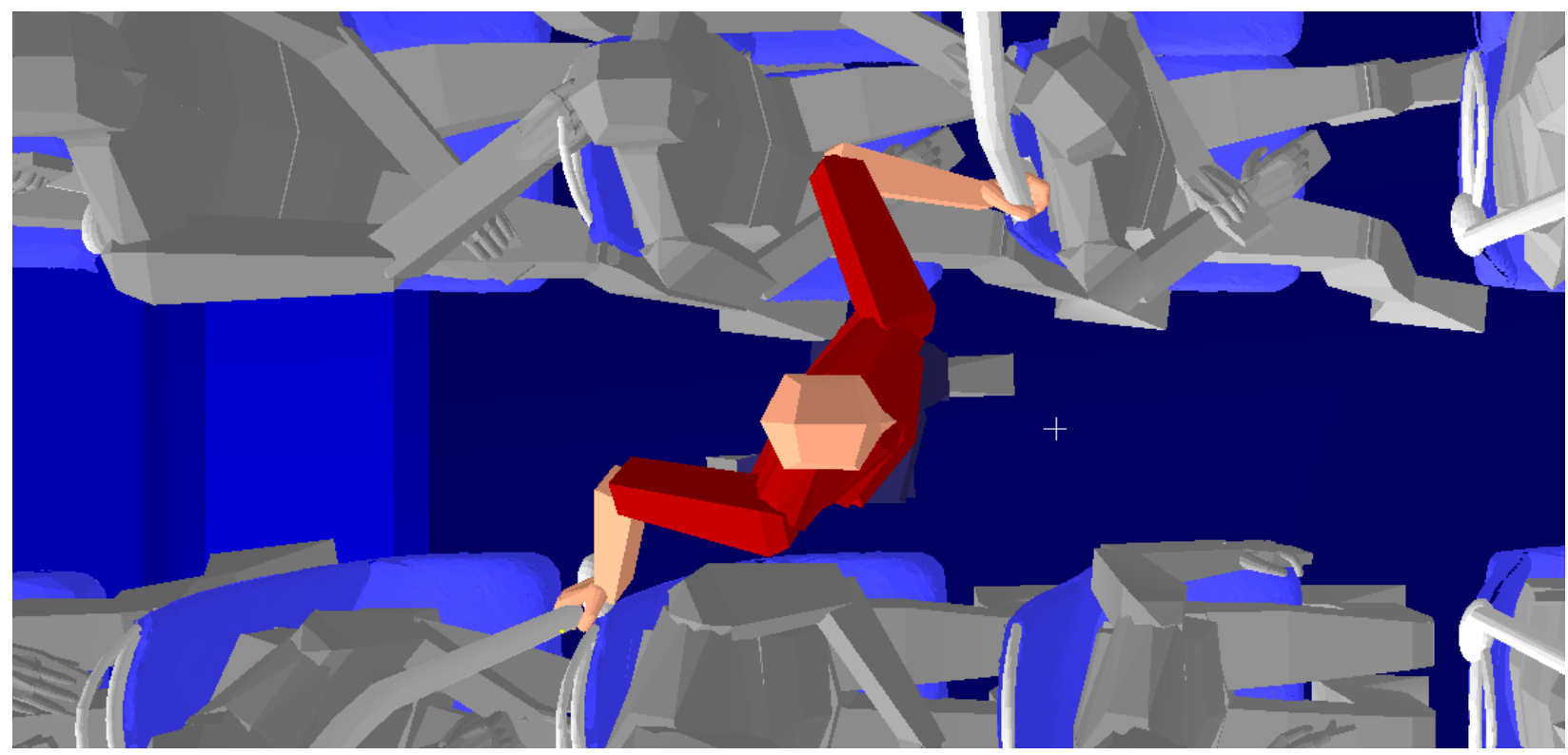

Figure 7. Human models would hold on to at least one hand hold within the vehicle whilst traversing.

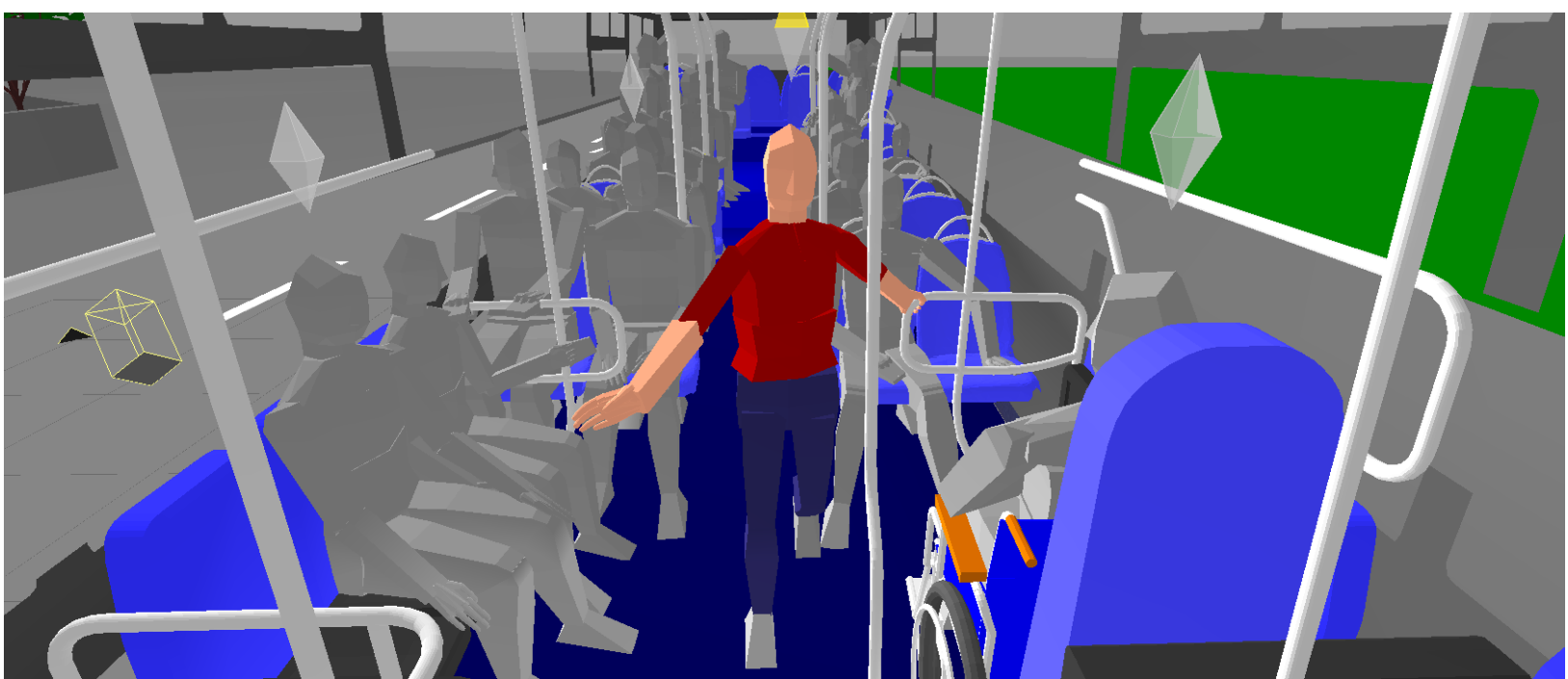

Figure 8. P13 moves forwards maintaining grip of the left hand handle but finds there is no conveniently placed right hand handle. 


\section{COGITATIO}

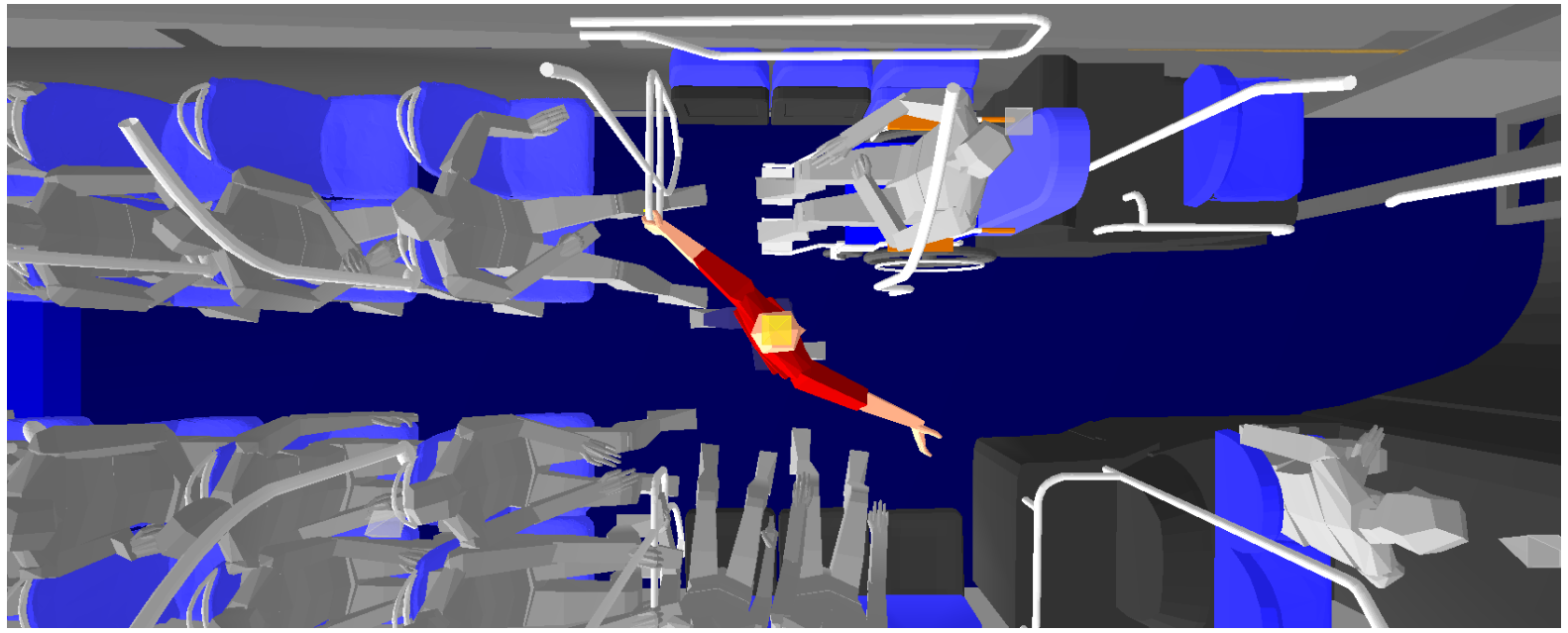

Figure 9. Plan view of P13 showing no conveniently located right hand grip.

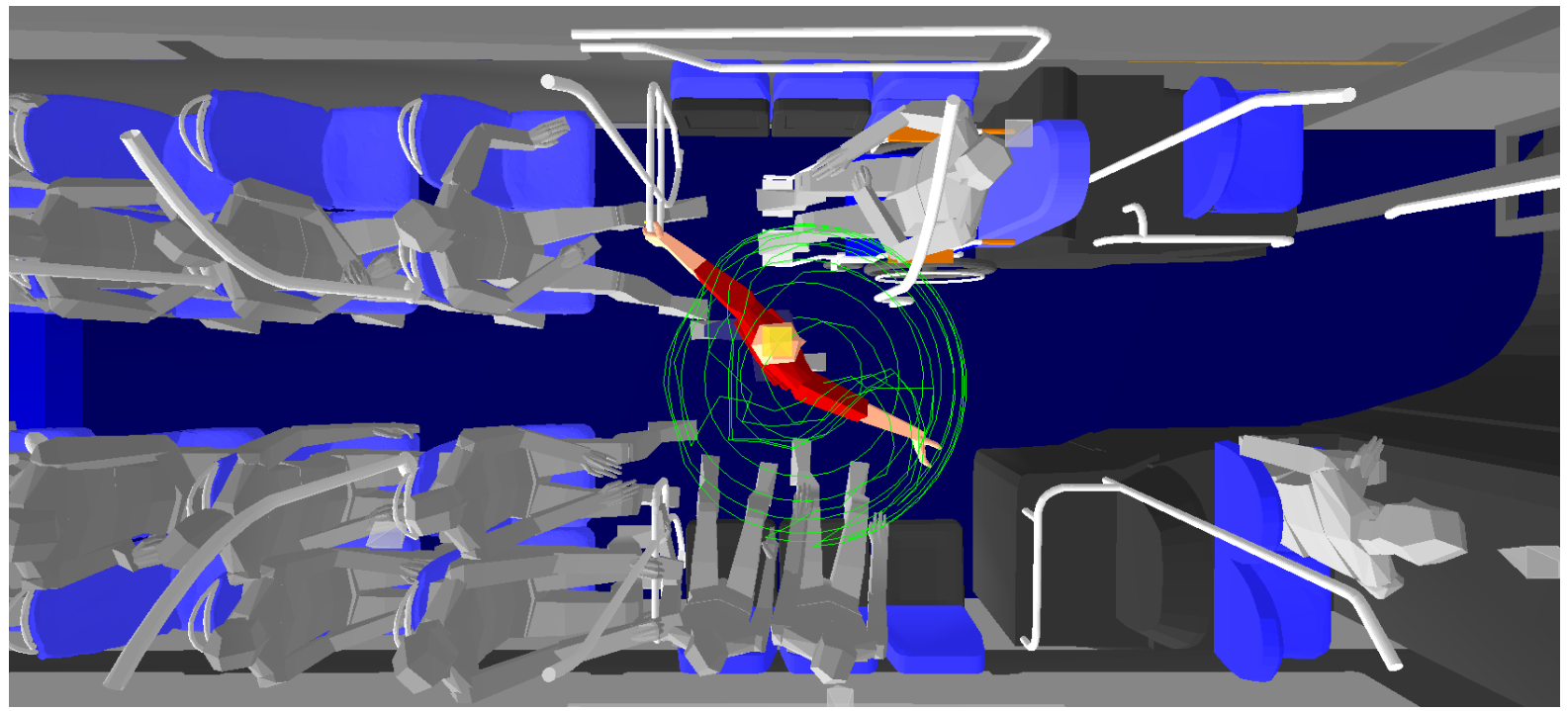

Figure 10. Reach contour for P13 confirming the lack of right hand handle, but also indicating the availability of the next left hand upright.

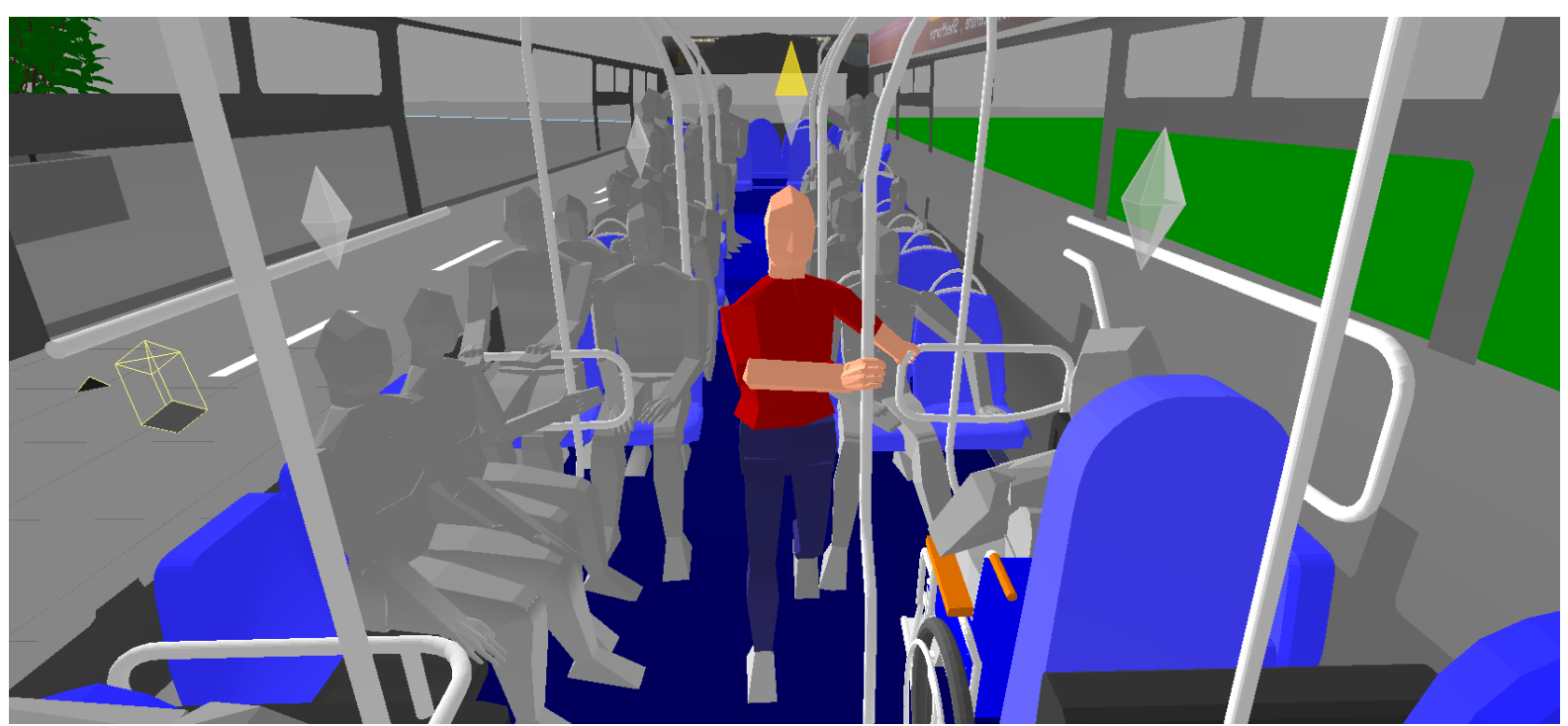

Figure 11. P13 moves forwards gripping the next left hand upright with the right hand. 
Figure 10 shows 'reach contours' for the right hand with a palm grip. This reach evaluation tool gives an idea of the reachable volume of space afforded to the human model in the posture shown. This highlights what hand holds may be within reach. In this case no handholds to the right are within reach, however P13 could potentially reach for the hand hold to their left.

Figure 11 and Figure 12 show the posture required to move forward through this area, maintaining grip. Due to the lack of a suitable handhold to the right, the left hand upright could be gripped with the right hand. Beyond this point the passenger would need to bring their left hand forward to join the right hand, both holding onto the left hand upright as shown in Figure 13. Moving further forward an alternate right-left grip could be resumed.

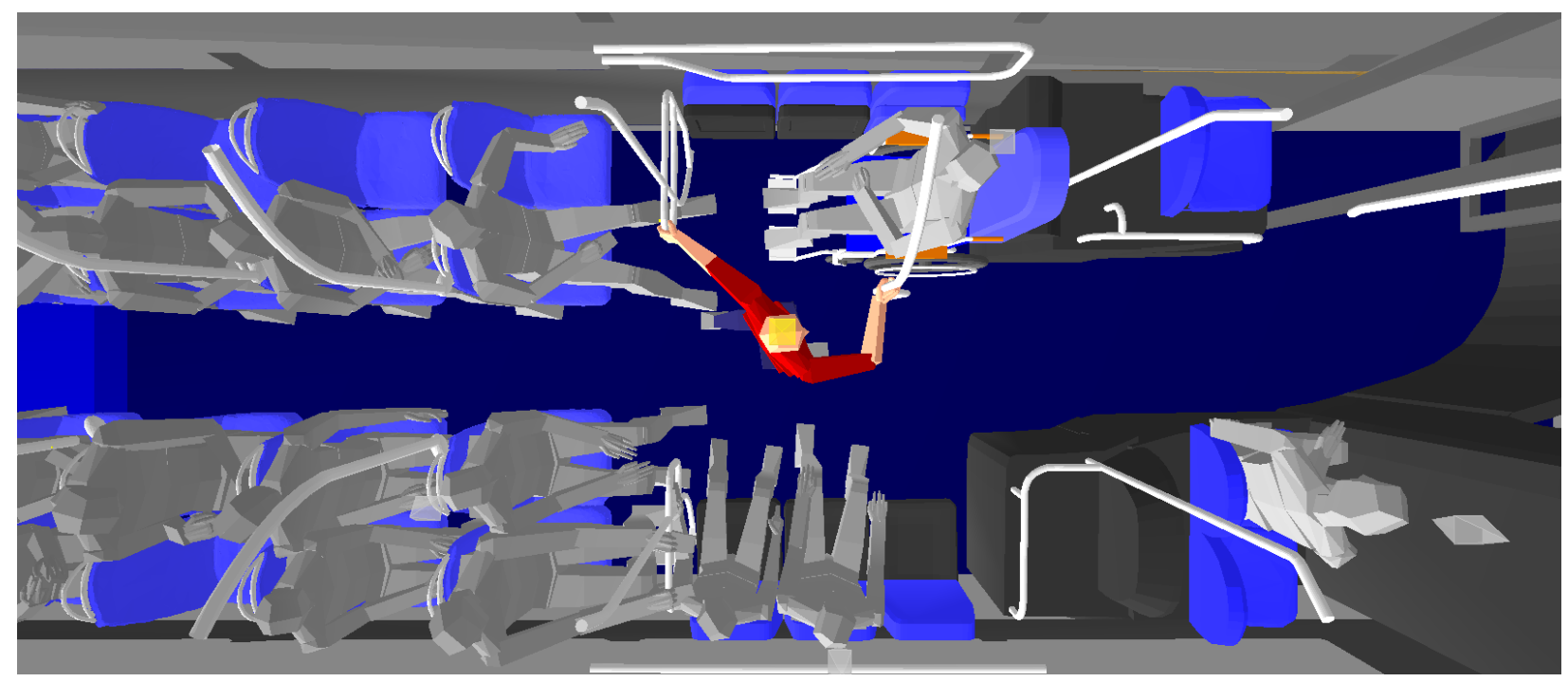

Figure 12. Plan view of the P13 showing the grip of the two left hand handles.

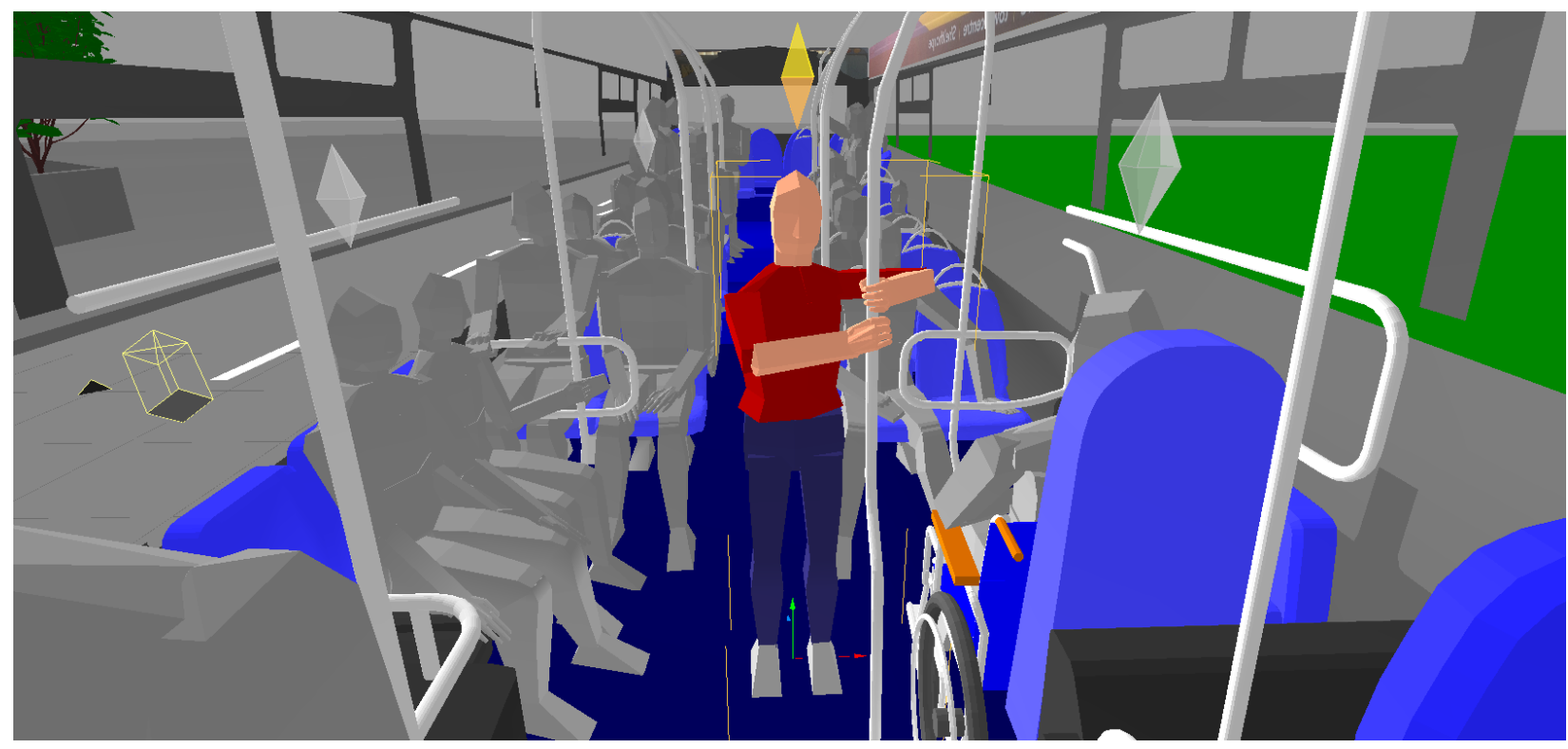

Figure 13. P13 moves forwards resulting a double handed grip of the left hand upright.

The results of the analysis with one exemplar task and user described here, shows how the use of human modelling can be used to explore issues with transport designs and infrastructure. Whilst beyond the scope of this paper the research also explored other scenarios such as seated passengers and also possible design interventions. In brief, there were three main findings:
- The transverse seating area has a reduced availability of hand holds for passengers standing or traversing through this area. The use of digital modelling and simulation could be used to explore the addition of more upright handholds to improve the situation for standing passengers but also to explore any effect on wheelchair and pushchair user needs in an attempt to provide a universal solution 
- The assessment performed has highlighted that the current configuration may need a two handed grip at certain points during the traversal through the vehicle. In many instances this would be impractical or impossible due to the number of potential travelers who would be holding a personal items such as a bag, stick, umbrella or other encumbrance (see Barnes et al., 2013, for further detail of this scenario)

- The seat back handholds are important in the forward facing seating area but are probably secondary for most passengers as the uprights provide improved, unobstructed access. The use of digital modelling and simulation could be used to explore the implication of providing redesigned seat back mounted handles to allow access that is unobstructed by other seated passengers

More broadly the use of digital human modelling technologies combined with improved data on a broader range of the population has the ability to support a more inclusive approach to transport design and planning. Designers, engineers, and planners are often faced with data on accessibility issues but do not always have the ability to explore the nature of the barrier to accessibility nor to simulate potential improvements. The case study example described here provides a brief insight into how such tools can offer benefits in this area. However, the simulation shown is for one individual and yet most inclusivity issues concern the needs of populations, public transport must be designed to meet the needs of the majority of users and not reflect individual user needs.

\section{Exploring the Representativeness of the HADRIAN Database}

From its inception the sampling strategy of the HADRIAN database attempted to capture data from participants with an even distribution across each of the measures recorded. For example the database has participants with an age in every decile between the 10 's (18yrs) to the 80's (89yrs), in every decile for percentile stature for both males (1st-99th) and females (1st-98th) etc. However, it was always understood that even with careful sampling the 102 individuals would never be representative of a whole population. It is therefore important to discuss the value of any results gained from the exploration of accessibility issues with members of the HADRIAN virtual user group in the context of their ability to inform decisions that affect whole populations.

In the previous section a single individual is used in an assessment. With a single participant, insights into usability can still be obtained. However, drawing broader conclusions regarding the needs of a design aimed at the broadest range of users is not straightforward. The insights gained cannot necessarily be used to support a design intervention without further understanding of the implications of the intervention on other users. If the case study in the previous section were repeated with the whole HADRIAN user group the results would be much broader in scope. More insights would be generated and there is a greater likelihood that conflicting requirements would be highlighted and subsequently support an opportunity to evaluate any necessary trade-offs if an intervention were to be made. Validation work with the database does support this claim with many of the insights generated by the use of HADRIAN reflecting those observed in real-world evaluations (Marshall et al., 2013; Summerskill et al., 2009). Yet the issue of representativeness is still a potential concern. As a counterpoint to these concerns, real world testing of physical products tends to utilise relatively modest numbers of people. For example research has shown that the majority of issues can be identified with as few as four or five participants (McClelland, 1995). As such a user group of 102 might be considered to be of a good size to explore the majority of requirements. Indeed it is not uncommon for designers to use socalled personas to aid in the development of products and services (Saffer, 2007). These personas are research based archetypal users, employed by a design team to maintain focus on user needs. Typically between one and seven personas would be employed on a project (Marshall et al., 2013). In research by Goodman-Deane, Langdon, and Clarkson (2010) personas are highlighted as one of a number of methods that are engaging for designers suiting their informal and flexible ways of working. Whilst the HADRIAN database and its virtual user group are not personas in the traditional sense, they do offer similar characteristics particularly in the ability to foster engagement with end users (Högberg, Lundström, Hanson, \& Wårell, 2009).

\section{Disability Follow Up Survey of Great Britain}

To explore these issues further, recent work on the HADRIAN database has investigated the ability to inform practitioners on the representativeness of the individuals in the HADRIAN user group. The approach taken has been to compare the capabilities of the individuals in the database to the data in the Office of National Statistics' (ONS) Disability Follow-up Survey (DFS) conducted in 1996/1997. This survey aimed to collect information about the prevalence of disability in Great Britain and the characteristics of those who were disabled (Grundy, Ahlburg, Ali, Breeze, \& Sloggett, 1999).

The DFS survey was established to understand and 
measure the ability to perform certain tasks that were divided into ability categories. Individuals were selected on the basis of certain criteria, for example, the receipt of benefits and an age greater than 16 years. To measure the level of disability, approximately three hundred questions were asked of 7300 participants, covering a variety of ability categories. A total of ten categories are defined including: Locomotion; Reaching and Stretching; Dexterity; Seeing; Hearing; Personal Care; Continence; Communication; Behaviour and Intellectual functioning. The questions largely concerned a self-assessment requiring participants to identify their ability to perform tasks, and the relative ability in that task, associated with each category, such as:

- Cannot walk at all

- Can only walk up and down a flight of stairs if goes sideways or one step at a time

or

- Cannot see well enough to recognise a friend across a room

- Cannot see well enough to recognise a friend across a road

The resulting responses were then evaluated by an expert panel so that an overall consensus on a disability scale might be achieved (Martin \& Elliot, 1992). These scales were arranged in such a manner that the higher the value of severity score, the greater the severity of a particular disability. For example, a person with a reaching and stretching severity score of 9.5 (RS1-Reach and stretch level 1) has a more severe disability as compared with a person with a 5.5 (RS6) severity score. In this way, the data were used to measure the level of disability and estimate disability prevalence in the overall UK population at that time.

\section{The Disability Follow Up Survey Severity Scales}

One of the significant characteristics of the DFS is the view taken of disability and its categorisation focusing on practical abilities rather than medical definition. Thus the severity of a disability is defined as the extent to which an individual's performance of activities is limited by impairments (Martin, Meltzer, \& Elliot, 1988). After developing scales for each category, there was a need to assess the overall impact of these impairments on an individual's ability/disability. The overall severity scale was constructed according to the formula:

Worst (score in any category) +0.4 (second worst) +0.3 (third worst)

The above formula was applied to everyone in the survey to calculate an overall severity score for each person. Finally, these overall severity scores were grouped into the ten severity categories; their levels and ranges are shown in the table 1.

During the data collection for the HADRIAN database, relevant scales from the DFS were used for the assessment of level and severity of disability from all 102 participants. Because of this similarity in severity scales used in the HADRIAN database and the DFS, it might be said that the individuals presented in the database, are similar in some specific ability categories with the population represented by the ONS data.

The common severity scales used for different areas of disability in the disability survey and the HADRIAN database; are presented in tables 2 to 5 . Only four of the ten categories were used due to practical constraints in data collection and the focus being primarily on physical rather than cognitive abilities.

Similar scales were developed for the other categories by the DFS however discussion here is limited to those which HADRIAN and the disability survey have in common.

Table 1. Levels of disability severity in accordance with overall severity scores Sources: Grundy et al. (1999) and Martin et al. (1988).

\begin{tabular}{ll}
\hline Severity category & Overall severity score \\
\hline 10 (most severe) & 19 or higher \\
9 & $17-18.95$ \\
8 & $15-16.95$ \\
7 & $13-14.95$ \\
6 & $11-12.95$ \\
5 & $9-10.95$ \\
4 & $7-8.95$ \\
3 & $5-6.95$ \\
2 & $3-4.95$ \\
1 (least severe) & $0.5-2.95$ \\
\hline
\end{tabular}




\subsection{Locomotion}

Table 2. Different levels of locomotion ability and respective severity scores. Sources: Grundy et al. (1999) and Martin et al. (1988).

\begin{tabular}{llc}
\hline Level & Question & Severity Score \\
\hline L1 & Cannot walk at all & $\mathbf{1 1 . 5}$ \\
L2 & Can only walk a few steps without stopping or severe discomfort/cannot walk up and down one & $\mathbf{9 . 5}$ \\
& step & $\mathbf{7 . 5}$ \\
$\mathbf{L 3}$ & Has fallen 12 or more times in the last year & $\mathbf{7 . 0}$ \\
L4 & Always needs to hold on to something to keep balance & $\mathbf{6 . 5}$ \\
L5 & Cannot walk up and down a flight of 12 stairs & $\mathbf{5 . 5}$ \\
L6 & Cannot walk 50 yards without stopping or severe discomfort & $\mathbf{4 . 5}$ \\
L7 & Cannot bend down far enough to touch knees and straighten up again & $\mathbf{4 . 0}$ \\
L8 & Cannot bend down and pick something up from the floor and straighten up again & $\mathbf{3 . 0}$ \\
L9 & Cannot walk 200 yards without stopping or severe discomfort/Can only walk up and down a & \\
& flight of 12 stairs if holds on and takes a rest/Often needs to hold on to something to keep & $\mathbf{2 . 5}$ \\
$\mathbf{L 1 0}$ & balance/Has fallen 3 or more times in the last year & $\mathbf{2 . 0}$ \\
L11 & Can only walk up and down a flight of 12 stairs if holds on (doesn't need a rest) & $\mathbf{1 . 5}$ \\
L12 & Can only wend down to sweep up something from the floor and straighten up again & $\mathbf{0 . 5}$ \\
L13 & Cannot walk 400 yards without stopping or severe discomfort & \\
\hline
\end{tabular}

\subsection{Reaching and Stretching}

Table 3. Different levels of reaching and stretching ability, and respective severity scores. Sources: Grundy et al. (1999) and Martin et al. (1988).

\begin{tabular}{llc}
\hline Level & Question & Severity Score \\
\hline RS1 & Cannot hold out either arm in front to shake hands & $\mathbf{9 . 5}$ \\
RS2 & Cannot put either arms up to head to put a hat on & $\mathbf{9 . 0}$ \\
RS3 & Cannot put either hand behind back to put jacket on or tuck shirt in & $\mathbf{8 . 0}$ \\
RS4 & Cannot raise either arm above head to reach for something & $\mathbf{7 . 0}$ \\
RS5 & Has difficulty holding either arm in front to shake hands with someone & $\mathbf{6 . 5}$ \\
RS6 & Has difficulty putting either arm up to head to put a hat on & $\mathbf{5 . 5}$ \\
RS7 & Has difficulty putting either hand behind back to put jacket on or tuck shirt in & $\mathbf{4 . 5}$ \\
RS8 & Has difficulty raising either arm above head to reach for something & $\mathbf{3 . 5}$ \\
RS9 & Cannot hold one arm out in front or up to head (but can with other arm) & $\mathbf{2 . 5}$ \\
RS10 & Cannot put one arm behind back to put on jacket or tuck shirt in (but can with other arm)/Has & $\mathbf{1 . 0}$ \\
& difficulty putting one arm behind back to put jacket on or tuck shirt in, or putting one arm out & \\
& in front or up to head (but no difficulty with other arm) &
\end{tabular}

\subsection{Dexterity}

Table 4. Different levels of dexterity and respective severity scores. Sources: Grundy et al. (1999) and Martin et al. (1988).

\begin{tabular}{llc}
\hline Level & Question & Severity Score \\
\hline D1 & Cannot pick up and hold a mug of coffee with either hand & $\mathbf{1 0 . 5}$ \\
D2 & Cannot turn a tap or control knobs on a cooker with either hand & $\mathbf{9 . 5}$ \\
D3 & Cannot pick up and carry a pint of milk or squeeze the water from a sponge with either hand & $\mathbf{8 . 0}$ \\
D4 & Cannot pick up a small object such as safety pin with either hand & $\mathbf{7 . 0}$ \\
D5 & Has difficulty picking up and pouring from a full kettle or serving food from a pan using a & $\mathbf{6 . 5}$ \\
& spoon or ladle & $\mathbf{5 . 5}$ \\
D6 & Has difficulty unscrewing the lid of a coffee jar or using a pen or pencil & $\mathbf{4 . 0}$ \\
D7 & Cannot pick up and carry a 5lb bag of potatoes with either hand & $\mathbf{3 . 0}$ \\
D8 & Has difficulty wringing out light washing or using a pair of scissors & $\mathbf{2 . 0}$ \\
D9 & Can pick up and hold a mug of tea or coffee with one hand but not with the other & $\mathbf{1 . 5}$ \\
D10 & Can turn a tap or control knob with one hand but not with the other/Can squeeze the & $\mathbf{0 . 5}$ \\
& water from a sponge with one hand but not the other & \\
D11 & Can pick up a small object such as a safety pin with one hand but not with the other/Can & pick up and carry a pint of milk with one hand but not the other/Has difficulty tying a bow \\
& in laces or strings & \\
\hline
\end{tabular}




\subsection{Personal Care}

Table 5. Different levels of personal care ability and respective severity scores. Sources: Grundy et al. (1999) and Martin et al. (1988).

\begin{tabular}{llc}
\hline Level & Question & Severity Score \\
\hline PC1 & Cannot feed self without help/Cannot go to and use the toilet without help & $\mathbf{1 1 . 0}$ \\
PC2 & Cannot get into and out of bed without help/Cannot get into and out of chair without help & $\mathbf{9 . 5}$ \\
PC3 & Cannot wash hands and face without help/Cannot dress and undress without help & $\mathbf{7 . 0}$ \\
PC4 & Cannot wash all over without help & $\mathbf{4 . 5}$ \\
PC5 & Has difficulty feeding self/Has difficulty getting to and using the toilet & $\mathbf{2 . 5}$ \\
PC6 & Has difficulty getting in and out of bed/Has difficulty getting in and out of a chair & $\mathbf{1 . 0}$ \\
\hline
\end{tabular}

\section{Population Estimation for the DFS}

The DFS aimed to produce national estimates about the number of people with different levels of severity of disability in Great Britain. The sample of 7300 people was statistically treated to estimate the number of people in the country with a similar level of disability. In this way, the proportions of the UK adult population ( +16 years) with the listed levels of disabilities were estimated. The results of this survey were first published in 'Disability in Great Britain' by the Department of Social Security in their research report number 94 (Grundy et al., 1999; Martin et al., 1988).

Figure 14 provides the percentage of the UK adult population (16+ years of age) in each disability severity level for two different disability categories. For example, in both of these categories level 9 (L9 and R9) are the most common. The locomotion ability level associated with L9 (Table 2) is exhibited by just over 3 percent of the overall UK population. Similarly, reach and stretch level R9 (Table 3) occurs in just under 1 percent of the UK adult population.

From these percentages, it is possible to estimate the total number of persons in the UK population with a given ability level. By multiplying the percentage associated with a level (e.g. L9, approx. 3.1\%) with the total adult population ( $45.6 \mathrm{M}$ at the time of the survey), the total number is estimated at about $1.41 \mathrm{M}$ persons in the UK adult population with this level of locomotion ability. In the same way, estimations against different areas of disability and levels of disability can be easily made.

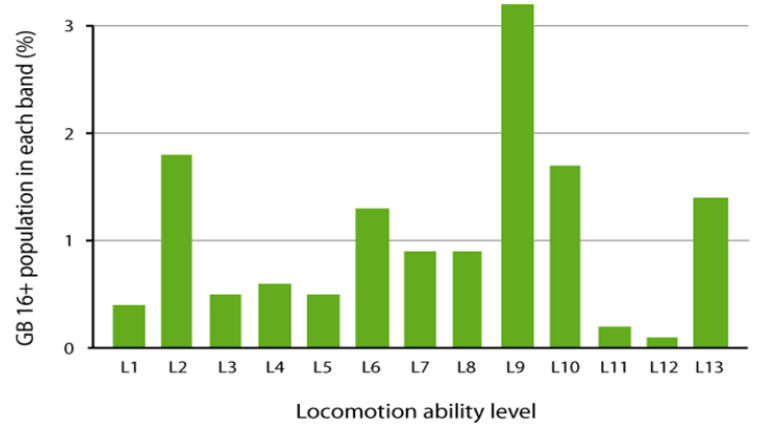

\section{HADRIAN Database Correlation with DFS}

As described earlier HADRIAN has a database of 102 individuals which represents a variety of people on the basis of their abilities, shapes, sizes and behaviours. The database also contains a disability severity score for each individual in line with the DFS. This provides a means to provide an indication of how prevalent the ability level of a single individual in the HADRIAN database is within the UK population. Or alternatively, and more usefully in the context of design, if an individual in the HADRIAN database is excluded during the evaluation of a design, it is possible to provide a broad indication of the proportion of the UK population that would be similarly excluded.

Being able or unable to do some task under a specific capability category, describes an individual's ability to comfortably interact with products, services or environments. The DFS disability data were intended for the purpose of indicating the capability of individuals to perform certain tasks. Some of the questions also inquire about specific product, service and environment interactions. A number of the same questions were also put to the HADRIAN participants so that selfreported abilities, together with, their recorded task behaviours, coping strategies and comfortable postures could be coded into the digital human modelling system. In this manner the difficulties identified through the use of the HADRIAN virtual user group are in some way able to provide a broader view of issues likely to be faced by the population.

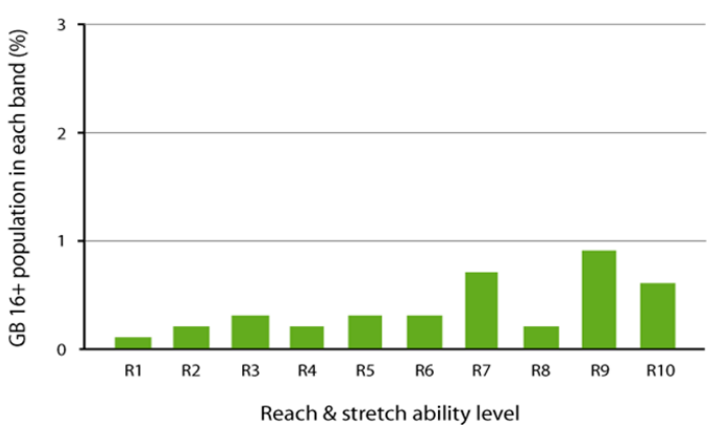

Figure 14. Disability prevalence data from the DFS for locomotion (L1 to L13 are the questions listed in table 2) and reach \& stretch (R1 to R10 are the questions listed in table 3). From the Inclusive design toolkit: user capabilities. Source: Clarkson, Coleman, Hosking, and Waller (2015). 
As an example Table 6 and Table 7 show the locomotion and reaching and stretching ability levels of the HADRIAN participants, their prevalence within the database and the estimation of their prevalence in the UK population through the DFS. The final column also provides an indication of the number of the population who may be excluded if a participant with a given severity score in the database were excluded.

The data shown in the tables above provide an example of how the capabilities of the individuals in the HADRIAN user group could be used as indicators of the capabilities of the population. They also provide an example of how simulation tools more broadly could be used to support population level decisions and policies. Table 6 shows that there are 102 individuals in the da- tabase of which 63 have no impairment to their locomotion that registers on the DFS scales. As we know that the HADRIAN database has used the same method for severity level assessment as used in the DFS, it can be said that there are 63 individuals in this database whose locomotion ability is representative of about 39.5 million of the UK adult population. Exploring further there are 6 individuals in the database with a locomotion severity score 6.5 (L5). It can be estimated that there are about 226,000 people in the population with a similar level of locomotion capability. In terms of application, these correlations allow analyses performed with individuals from the HADRIAN database to be place in a broader context. As an example, a task may require a user to climb a flight of 20 steps to access a

Table 6. HADRIAN severity scores and DFS-based population estimation for locomotion.

\begin{tabular}{|c|c|c|c|c|c|}
\hline $\begin{array}{l}\text { Locomotion } \\
\text { severity score } \\
\text { (L) }\end{array}$ & $\begin{array}{l}\text { Number of } \\
\text { persons in the } \\
\text { HADRIAN } \\
\text { database }\end{array}$ & $\begin{array}{l}\text { Population } \\
\text { estimation from } \\
\text { the DFS } \\
\text { (Thousands) }\end{array}$ & $\begin{array}{l}\text { Population } \\
\text { estimation } \\
\text { from the DFS } \\
(\%)\end{array}$ & $\begin{array}{l}\text { Cumulative } \\
\text { population estimation } \\
\text { from the DFS } \\
\text { (Thousands) }\end{array}$ & $\begin{array}{l}\text { Cumulative } \\
\text { population } \\
\text { estimation from } \\
\text { the DFS } \\
\text { (\%) }\end{array}$ \\
\hline No disability & 63 & 39,455 & $86.5 \%$ & 45,600 & $100.0 \%$ \\
\hline L13 (0.5) & 0 & 626 & $1.4 \%$ & 6,145 & $13.5 \%$ \\
\hline L12 (1.5) & 0 & 41 & $0.1 \%$ & 5,518 & $12.1 \%$ \\
\hline $\operatorname{L11}(2.0)$ & 0 & 110 & $0.2 \%$ & 5,477 & $12.0 \%$ \\
\hline $\operatorname{L10}(2.5)$ & 6 & 784 & $1.7 \%$ & 5,367 & $11.8 \%$ \\
\hline L9 (3.0) & 11 & 1,438 & $3.2 \%$ & 4,583 & $10.1 \%$ \\
\hline L8 (4.0) & 0 & 414 & $0.9 \%$ & 3,145 & $6.9 \%$ \\
\hline L7 (4.5) & 1 & 398 & $0.9 \%$ & 2,730 & $6.0 \%$ \\
\hline L6 (5.5) & 1 & 598 & $1.3 \%$ & 2,332 & $5.1 \%$ \\
\hline L5 (6.5) & 6 & 226 & $0.5 \%$ & 1,735 & $3.8 \%$ \\
\hline L4 (7.0) & 5 & 256 & $0.6 \%$ & 1,508 & $3.3 \%$ \\
\hline L3 (7.5) & 3 & 221 & $0.5 \%$ & 1,253 & $2.7 \%$ \\
\hline L2 (9.5) & 1 & 833 & $1.8 \%$ & 1,031 & $2.2 \%$ \\
\hline L1 (11.5) & 5 & 198 & $0.4 \%$ & 198 & $0.4 \%$ \\
\hline Total & 102 & 45600 & & & \\
\hline
\end{tabular}

Table 7. HADRIAN severity scores and DFS-based population estimation for reach and stretch.

\begin{tabular}{|c|c|c|c|c|c|}
\hline $\begin{array}{l}\text { Reach and } \\
\text { Stretch severity } \\
\text { score } \\
\text { (L) }\end{array}$ & $\begin{array}{l}\text { Number of } \\
\text { persons in the } \\
\text { HADRIAN } \\
\text { database }\end{array}$ & $\begin{array}{l}\text { Population } \\
\text { estimation from } \\
\text { the DFS } \\
\text { (Thousands) }\end{array}$ & $\begin{array}{l}\text { Population } \\
\text { estimation } \\
\text { from the DFS } \\
\text { (\%) }\end{array}$ & $\begin{array}{l}\text { Cumulative } \\
\text { population estimation } \\
\text { from the DFS } \\
\text { (Thousands) }\end{array}$ & $\begin{array}{l}\text { Cumulative } \\
\text { population } \\
\text { estimation from } \\
\text { the DFS } \\
(\%)\end{array}$ \\
\hline No disability & 81 & 43,859 & $96.2 \%$ & 45,600 & $100.0 \%$ \\
\hline RS10 (1.0) & 5 & 279 & $0.6 \%$ & 1,741 & $3.8 \%$ \\
\hline RS9 (2.5) & 15 & 390 & $0.9 \%$ & 1,462 & $3.2 \%$ \\
\hline RS8 (3.5) & 0 & 113 & $0.3 \%$ & 1,072 & $2.4 \%$ \\
\hline RS7 (4.5) & 1 & 306 & $0.7 \%$ & 959 & $2.1 \%$ \\
\hline RS6 (5.5) & 0 & 159 & $0.4 \%$ & 653 & $1.4 \%$ \\
\hline RS5 (6.5) & 0 & 130 & $0.3 \%$ & 494 & $1.1 \%$ \\
\hline RS4 (7.0) & 0 & 90 & $0.2 \%$ & 364 & $0.8 \%$ \\
\hline RS3 (8.0) & 0 & 159 & $0.4 \%$ & 274 & $0.6 \%$ \\
\hline RS2 (9.0) & 0 & 69 & $0.2 \%$ & 116 & $0.3 \%$ \\
\hline RS1 (9.5) & 0 & 47 & $0.1 \%$ & 47 & $0.1 \%$ \\
\hline Total & 102 & 45600 & & & \\
\hline
\end{tabular}


train station platform. This platform has no lift or ramp and thus the steps are the only means of access. A locomotion severity score of 6.5 (L5) is defined as "cannot walk up and down a flight of 12 stairs" and thus individuals categorised as $L 5$ would not be able to complete the task and would be excluded from catching trains at the station. From the population estimations, it would also be possible to conclude that up to 226,000 adults in the UK would also be excluded. However, it is also possible to assume that, if those categorised as L5 are excluded, anyone with a greater level of disability e.g. L1-L4 would also be excluded. The right hand column in Table 6 and Table 7 is estimated by cumulatively summing the numbers of the population in the current level of severity with all levels of greater severity. Thus for the train station example, a flight of 20 steps actually has the potential to exclude $1.7 \mathrm{M}$ adults in the UK based on locomotion alone.

Returning to the bus simulations described earlier. The perception may be that there are some modest issues with traversing a bus for older passengers. If we place the results in context and evaluate the impact with more of the HADRIAN sample a clearer result can be obtained that may support the need for an intervention. For example if the assessment was repeated with participant 92, an 83 year old female, who has a reaching and stretching severity score of 2.5 (RS9), defined as "cannot hold one arm out in front or up to head (but can with other arm)" it is likely that this individual could not complete the task. As shown earlier, it is likely that two hands would be required to provide an older passenger with the ability to brace themselves against movement of the vehicle. The implication on P92 not being able to complete the task is that up to $1.5 \mathrm{M}$ people in the UK adult population would also be unable to complete the task. Thus, the conclusion might be drawn that the UK has buses in general service that are potentially dangerous for more than a million people within the current adult population if standing whilst the bus is moving. This conclusion is not particularly unexpected as it is well understood that passengers and particularly those who are older should not stand on a moving bus. Equally from discussion with bus operators and drivers, training suggests that drivers should not move off until older passengers are seated. However, these situations do occur and the accident data shows that older people continue to be injured and killed in these situations. Simulations such as those shown above, together with the ability to extrapolate the results to provide an indication of the magnitude of an issue at a population level, provide a means to obtain objective data to inform whether an intervention should be made.

\section{Discussion}

The potential of simulation tools such as HADRIAN that combine rich and applicable data on people together with the ability to assess existing or future designs provide an opportunity to evaluate accessibility in a proactive manner. This simulation capability can then be used to further explore issues that may be identified through a range of other sources from focus groups through to accident data. This understanding can focus on the detail such as causation, or can take a broader look at the potential impact of the issue through the potential to quantify the magnitude of the problem. As discussed, identifying a number of individuals who have a problem with a given design or environment is useful, however being able to gain in insight into the broader representation of these problems within the population has the potential to support decision making on possible interventions or design decisions in a much clearer manner.

However, this approach is not without its complexities. The correlation of individuals in the HADRIAN database with population estimations has to be considered with care. In the first instance the DFS survey was of 7300 people from which they have statistically extrapolated the representativeness to the whole UK adult population. So in many ways the concept is extrapolating one individual's capabilities to a proportion of 7300 people to a proportion of the UK population. This includes many assumptions and this requires the totals to be taken in an advisory context. Furthermore the DFS survey is now nearly 20 years old. The data within it are likely to be less representative of the population than they were particularly with an ageing population. It can be seen that in the 20 years since the survey was conducted the proportion of the UK population that is 65 years and over has increased from $15.8 \%$ to $17.7 \%$. In addition the population itself has increased from $45.6 \mathrm{M}$ adults to $52.25 \mathrm{M}$ (Office for $\mathrm{Na}$ tional Statistics, 2015). The implications of these changes is unknown and it may be possible to assume that an increasing older population would increase the prevalence of disability and increase the numbers in each of the DFS categories, making current estimations conservative. However our ageing population is also due to people living longer, thus our ageing population may be more able, making current estimations pessimistic.

The DFS survey itself is also somewhat problematic for this kind of application. As discussed by Waller, Langdon and Clarkson (2010) the DFS survey was never intended to support this kind of analysis and has its own limitations in sampling, interpretation of the responses and in the questions/categories it defines. For example the categories mix broad abilities. As described earlier, L5 is defined as "cannot walk up and down a flight of 12 stairs" whereas L7 is defined at "cannot bend down far enough to touch knees and straighten up again". The categories assume that someone at level $\mathrm{L} 5$ is more disabled than someone at L7, however being unable to walk up 12 stairs does not necessarily mean you cannot bend down to touch your 
knees. Whilst the categories have a broader scope than might be considered ideal, they can be largely described as univariate, dealing with one type of disability in each case. However, most tasks are multivariate. Requiring a combination of locomotion, reaching and stretching, dexterity etc. These combinations are not accounted for in this approach. If a HADRIAN participant has a combination of ability levels of which a number are relevant to a particular task, the exact reason they may be excluded may be difficult to filter out from the combined ability of that individual. For example, Participant 96 in the database is a wheelchairusing older woman, can only walk a few steps/cannot walk up or down one step (score 9.5 for Locomotion), cannot get in/out of bed without help (score 9.5 for Personal Care), has difficulty using a pen or pencil (score 5.5 for Dexterity), cannot hold one arm out in front or up to head (but can with other arm) (score 2.5 for Reaching and Stretching) may be excluded from a task for any combination of those factors. HADRIAN does provide some insight into a task failure and where this has a clear mapping to the DFS categories the population estimation may be clearly defined. Research such as that performed by Clarkson et al. (2015) has attempted to unpack some of the interrelated nature of these data in their inclusive design toolkit. However, further research is still required to address the limitations with the DFS data to make them ideally suited to this form of application. At present, for situations in which a task failure is attributed to an ability that crosses DFS categories the population estimation would be down to the practitioner using the system to decide the most relevant category to estimate the percentage of the population potentially affected.

\section{Conclusions}

In order to support practitioners in the development and implementation of socially inclusive policy and design changes, a software simulation tool called HADRIAN has been developed. HADRIAN works with a digital human modelling system called SAMMIE to allow virtual users to assess the accommodation of existing or planned designs. The use of the simulation tool, through a case study exploring the safety of standing passengers on UK buses, has highlighted the ability to identify accessibility issues for individuals within a virtual user group. Such an approach has the potential to provide an understanding for practitioners on the issues that might be faced by real people. Whilst only one virtual user has been shown in this paper, digital evaluations combined with automated analysis of virtual user-groups has the ability to evaluate the experiences of up to 102 virtual humans in the case of HADRIAN in a manner that is expedient, and avoids the ethical issues with real-world user trials. The experiences of the individuals are further explored through their correlation with the disability follow-up survey of Great Britain. Using the survey's findings, it is possible to make broad estimates of the potential population impact of an individual virtual user being excluded through poor design. The correlation process does have its own concerns as the original data were never intended to support his form of application and so the data must be treated with care. However, even with the acknowledged limitations, a further understanding of the potential representativeness of any simulation results would be beneficial. Together the approaches provide a possible means of exploring social inclusion and accessibility issues that consider individual user needs, whilst also providing a means to quantify the impact on the population of a policy or design change.

\section{Acknowledgements}

The authors gratefully acknowledge the support of the Engineering and Physical Sciences Research Council (EPSRC) and their Extending Quality Life (EQUAL) and Sustainable Urban Environments (SUE) programmes as well as the Medical Research Council (MRC) and their Lifelong Health and Wellbeing Programme (LLHW).

\section{Conflict of Interests}

The authors declare no conflict of interests.

\section{References}

3D Systems. (2015). 3D digital design and fabrication solutions. 3D Systems. Retrieved from http://www.3d systems.com

Barnes, J., Lawton, C., Morris, A., Marshall, R., Summerskill, S., Kendrick, D. . . Conroy, S. (2013). Improving safety for older public transport users (OPTU): A feasibility study (MRC Research Final Report). Loughborough, UK: Loughborough University.

Barnes, J., Morris, A., Welsh, R., Summerskill, S., Marshall, R., Kendrick, D. . . . Bell, J. (2015). Injuries to older users of buses in the UK. Public Transport, 8(1), 25-38. doi:10.1007/s12469-015-0113-8

Church, A., Frost, M., \& Sullivan, K. (2000). Transport and social exclusion in London. Transport Policy, 7, 195205.

Clarkson, P.J., Coleman, R., Hosking, I., \& Waller, S. (2015). Inclusive design toolkit. Inclusive design toolkit. Retrieved from: http://www.inclusivedesign toolkit.com

Department for Transport. (2001). Older people: Their transport needs and requirements (Technical Report). London: Department for Transport.

Department for Transport (2013). Reported road casualties Great Britain: 2012 (Annual Report). London: Department for Transport. 
FARO. (2015). Measurement Technologies. FARO. Retrieved from http://www.faro.com/home

Ford, A. C., Barr, S. L., Dawson, R. J., \& James, P. (2015). Transport accessibility analysis using GIS: Assessing sustainable transport in London. ISPRS International Journal of Geo Information, 4, 124-149. doi:10.3390/ ijgi4010124

Goodman-Deane, J., Langdon, P., \& Clarkson, J. (2010). Key influences on the user-centred design process. Journal of Engineering Design, 21(2-3), 345-373.

Green, J., Jones, A., \& Roberta H. (2014). More than A to B: The role of free bus travel for the mobility and wellbeing of older citizens in London. Ageing Society, 34, 472-494.

Grundy, E., Ahlburg, D., Ali, M., Breeze, E., \& Sloggett, A. (1999). Disability in Great Britain (Research Report 94). London: Corporate Document Services.

Gyi, D. E., Porter, J. M., \& Case, K. (2000). Design practice and "design for all". Proceedings of the IEA 2000/ HFES 2000 Congress (pp. 913-916). San Diego, CA: Human Factors and Ergonomics Society.

Högberg, D., Lundström, D., Hanson, L., \& Wårell, M. (2009). Increasing functionality of DHM software by industry specific program features (SAE Technical Paper 2009-01-2288). Warrendale, PA: SAE International.

Karou, S., \& Hull, A. (2012). Accessibility measures and instruments. In A. Hull, C. Silva, \& L. Bertolini (Eds.), COST Action TU1002-Accessibility instruments for planning practice (pp. 1-19). Brussels: COST Office.

Linder, S. H., \& Peters, B. G (1984). From social theory to policy design. Journal of Public Policy, 4(3), 237-259. doi:10.1017/S0143814X0000221X

Mackett, R. (2014). Has the policy of concessionary bus travel for older people in Britain been successful? Case Studies on Transport Policy, 2, 81-88. doi:10.10 16/j.cstp.2014.05.001

Mackett, R., Achuthan, K., \& Titheridge, H. (2008). AMELIA: A tool to make transport policies more socially inclusive. Transport Policy, 15(6), 372-378. doi:10.10 16/j.tranpol.2008.12.007

Mackett., R., \& Thoreau, R. (in press). Transport, social exclusion and health. Journal of Transport \& Health. doi:10.1016/j.jth.2015.07.006

Marshall, R., Case, K., Oliver, R. E., Gyi, D. E., \& Porter, J. M. (2002). A task based 'design for all' support tool. Robotics and Computer-Integrated Manufacturing, 18(3-4), 297-303.

Marshall, R., Case, K., Porter, J. M., Sims, R. E., \& Gyi, D. E. (2004). Using HADRIAN for eliciting virtual user feedback in 'design for all'. Journal of Engineering Manufacture, 218(9), 1203-1210.

Marshall, R., Case, K., Porter, J. M., Summerskill, S. J., Gyi, D. E., Davis, D., \& Sims, R. E. (2010). HADRIAN: A virtual approach to design for all. Journal of Engineering Design, 21, 253-273.

Marshall, R., Cook, S., Mitchell, V., Summerskill, S.,
Haines, V., Maguire, M., \& Case, K. (2013). Design and evaluation: End users, user datasets and personas. Applied Ergonomics, 46(B), 311-317. doi:10. 1016/j.apergo.2013.03.008

Martin, J., \& Elliot, D. (1992). Creating an overall measure of severity of disability for the office of population and census and surveys disability survey. Journal of Royal Statistical Society, 155(1), 121-140.

Martin, J., Meltzer, H., \& Elliot, D. (1988). The prevalence of disability among adults. London: Her Majesty's Stationary Office.

May, A. D., Kelly, C., Shepherd, S., \& Jopson, A. (2012). An option generation tool for potential urban transport policy packages. Transport Policy, 20, 162173.

McClelland, I. (1995). Product assessment and user trials. In E. N. Corlett \& J. R. Wilson (Eds.), Evaluation of human work (pp. 249-284). London: Taylor \& Francis.

Musselwhite, C., \& Haddad, H. (2010). Mobility, accessibility and quality of later life. Quality in Ageing and Older Adults, 11(1), 25-37.

Oliver, R., Gyi, D., Porter, J. M., Marshall, R., \& Case, K. (2001). A survey of the design needs of older and disabled people. In P. T. McCabe, M. A. Hanson, \& S.A Robertson (Eds.), Contemporary ergonomics (pp. 365-370). London: Taylor and Francis.

Office for National Statistics. (2015). Overview of the UK Population. Office for National Statistics. Retrieved from: http://www.ons.gov.uk/ons/dcp171776_4223 83.pdf

Porter, J. M., Marshall, R., Freer, M., \& Case, K. (2004). SAMMIE: A computer aided ergonomics design tool. In N. J. Delleman, C. M. Haslegrave, \& D. B. Chaffin, D.B. (Eds.), Working postures and movements, tools for evaluation and engineering (pp. 454-470). Boca Raton, FL: CRC Press.

Rye, T., \& Mykura, W. (2009). Concessionary bus fares for older people in Scotland: Are they achieving their objectives? Journal of Transport Geography, 17(6), 451-456. doi:10.1016/j.jtrangeo.2008.08.003

Saffer, D. (2007). Designing for interaction: Creating smart applications and clever devices. New York: AlGA Design Press.

Summerskill, S. J., Marshall, R., Case, K., Gyi, D. E., Sims, R. E., \& Davis, P. (2009). Validation of the HADRIAN system using an ATM evaluation case study. Lecture notes in computer science: Proceedings of the second international conference (pp. 727-736). San Diego, $\mathrm{CA}: \mathrm{HCl}$ International

Waller, S. D., Langdon, P. M., \& Clarkson, P. J. (2010). Using disability data to estimate design exclusion. Universal Access in the Information Society, 9(3), 195207.

Yigitcanlar, T., Sipe, N., Evans R., \& Pitot, M. (2007). A GIS-based land use and public transport accessibility indexing model. Australian Planner, 44(3), 30-37. doi:10.1080/07293682.2007.9982586 
About the Authors

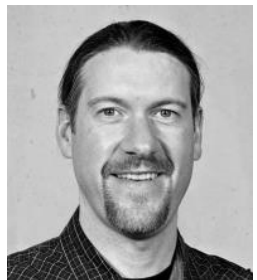

Russell Marshall is a senior lecturer and head of the Design Ergonomics Group in the Design School at Loughborough University. His research interests cover a broad range of topics within Product, Industrial and Engineering Design including: Digital Human Modelling and tools and techniques for facilitating and empowering designers in human-centred and inclusive design practice; Ergonomics and Human Factors in design, Modular product design, and drawing and visualisation. Russell is also principal developer of SAMMIE the digital human modelling system.

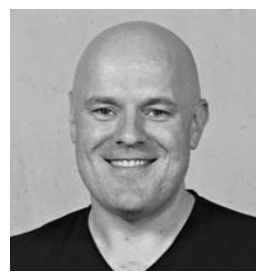

Steve Summerskill is a Senior Lecturer at Loughborough University. His research and enterprise activity exploit the combination of industrial design and ergonomics skill sets. Digital Human Modelling is a key tool in the research activities performed. A recent example of Steve's research is a project performed for the UK Department for Transport (DfT) which involved identifying a key blind spot associated with collisions between trucks and vulnerable road users, which led to revisions of European standards.

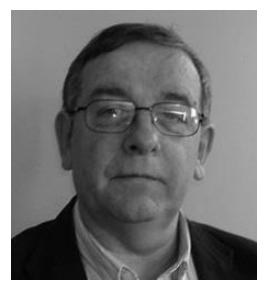

Keith Case is Professor of Computer Aided Engineering in Mechanical, Electrical and Manufacturing Engineering at Loughborough University and is a Chartered Engineer, Fellow of the Chartered Institute of Ergonomics \& Human Factors and a Fellow of the British Computer Society. In 1994 he received the Ergonomics Society Otto Edholm Award in recognition of his significant contribution to the development and application of ergonomics, primarily in the area of digital human modelling.

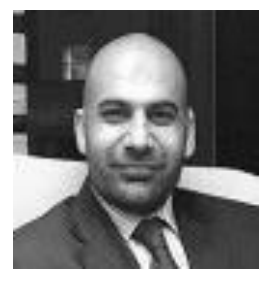

Amjad Hussain is an Associate Professor at the Department of Industrial \& Manufacturing Engineering, University of Engineering and Technology, Lahore, Pakistan. He gained his PhD in Human Factors/Ergonomics from Loughborough University, UK. His main focus research areas are: Engineering Design; Inclusive Design; Human Factors/Ergonomics; Digital Human Modelling; Socio-technical System Design; Automation; Corporate Social Responsibility (CSR); Ageing and Industrial Workplace Design.

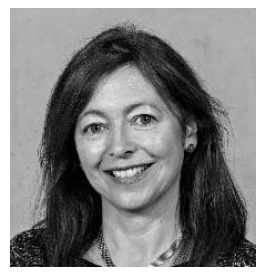

Diane Gyi is a Reader in Health Ergonomics and Design at Loughborough University. Her health background and knowledge of theory and practice has allowed her to integrate ergonomics into design, involving collaborations with over 50 organisations in grants to the value of over $f 3$ million. Applications of her work have covered topics as diverse as vehicle seating, inclusive design and healthy ageing. Diane is a member of the Editorial Boards for both the Journal of Industrial Ergonomics and Applied Ergonomics.

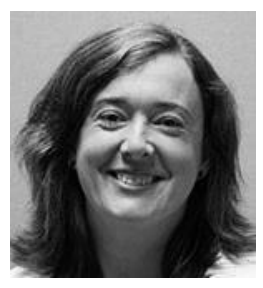

Ruth Sims is a senior lecturer in psychology and ergonomics at the University of Derby. Her background is predominantly in the area of inclusive design/design for all, particularly considering physical design issues for older and/or disabled people, but also including social and psychological aspects of inclusion both in the physical world and online. She teaches undergraduate social and developmental psychology, as well as on Masters level ergonomics and behaviour change programmes.

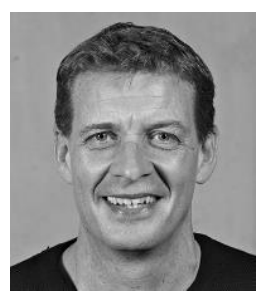

Andrew Morris has 27 years' experience in the field of road transportation safety, vehicle safety, accident investigation, crash-injury and driver behaviour research. Recently, he has worked as project leader within large European consortiums on behalf of the European Commission on a number of major road safety initiatives including the SafetyNet, PENDANT, TeleFOT and DaCoTA projects. He has published over 180 refereed technical publications, reports and conference papers in the subject of accident research, road crash injury, accident causation and driver behaviour.

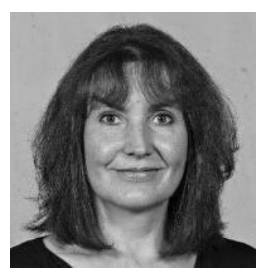

Jo Barnes is a Lecturer in the Design School having worked at Loughborough since 2005 initially as a researcher. She has a healthcare background in the area of traumatic injury and has spent over 15 years undertaking research in the area of road safety and injury prevention. Prior to coming to Loughborough University Jo held the position of Research Fellow in the Accident Research Centre at Monash University in Australia. 